\title{
Infrared spectra of protonated neurotransmitters: dopamine $\dagger$
}

\author{
Anita Lagutschenkov, ${ }^{a}$ Judith Langer, ${ }^{a}$ Giel Berden, ${ }^{b}$ Jos Oomens ${ }^{b c}$ and \\ Otto Dopfer* $*$
}

Received 12th October 2010, Accepted 16th November 2010

DOI: $10.1039 /$ c0cp02133d

The infrared (IR) spectrum of the isolated protonated neurotransmitter dopamine was recorded in the fingerprint range $\left(570-1880 \mathrm{~cm}^{-1}\right.$ ) by means of IR multiple photon dissociation (IRMPD) spectroscopy. The spectrum was obtained in a Fourier transform ion cyclotron resonance mass spectrometer equipped with an electrospray ionization source, which was coupled to a free electron laser (FEL). The spectroscopic studies are complemented by quantum chemical calculations at the B3LYP and MP2 levels of theory using the cc-pVDZ basis set. Several low-energy isomers with protonation occurring at the amino group are predicted in the energy range $0-50 \mathrm{~kJ} \mathrm{~mol}^{-1}$. Good agreement between the measured IRMPD spectrum and the calculated linear absorption spectra is observed for the two gauche conformers lowest in energy $(\Delta E)$ and free energy $(\Delta G)$ at both levels of theory, denoted $\mathbf{g}-\mathbf{1}$ and $\mathbf{g}+\mathbf{1}$. Minor contributions of higher lying gauche isomers cannot be ruled out spectroscopically but their calculated energies suggest only minor population in the sampled ion cloud. In all these gauche structures, one of the three protons of the ammonium group is pointing toward the catechol subunit, thereby maximizing the intramolecular $\mathrm{NH}-\pi$ interaction of the positive charge with the aromatic ring. In total, 16 distinct vibrational bands are observed in the IRMPD spectrum and assigned to individual normal modes of the energetically most stable $\mathbf{g}-\mathbf{1}$ conformer, with deviations of less than $24 \mathrm{~cm}^{-1}$ (average $11 \mathrm{~cm}^{-1}$ ) between measured and calculated frequencies. Comparison with neutral dopamine reveals the effects of protonation on the geometric and electronic structure.

\section{Introduction}

Neurotransmitters are endogenous chemical messenger compounds, which are responsible for signal transmission, enhancement, and modulation in the central and sympathetic nervous systems. ${ }^{1,2}$ Dopamine or 4-(2-aminoethyl)benzene-1,2-diol is a catecholamine and a fundamental representative of the group of neurotransmitters. As an adrenergic drug, it affects brain processes, which control movement and emotional response. As a hormone in vesicles of the adrenal medulla, it regulates the heart beat rate and the blood pressure. ${ }^{2,3}$ Dopamine receptors are also considered to be the major site of action of antipsychotic and anti-parkinsonism drugs. ${ }^{4}$ For example, parkinsonism is associated with a reduced dopamine level, whereas schizophrenia can be related to an increased dopamine activity. ${ }^{5}$

${ }^{a}$ Institut für Optik und Atomare Physik, Technische Universität Berlin, Hardenbergstrasse 36, 10623 Berlin, Germany.

E-mail:dopfer@physik.tu-berlin.de; Fax: + 49 30-31423018

${ }^{b}$ FOM Institute for Plasma Physics Rijnhuizen, Edisonbaan 14, 3439 MN Nieuwegein, The Netherlands

${ }^{c}$ University of Amsterdam, Science Park 904, Amsterdam 1098XH, The Netherlands

$\dagger$ Electronic supplementary information (ESI) available: Geometries, energies, charge distributions, fragment ion structures, and vibrational properties of various dopamine $\mathrm{H}^{+}$isomers and neutral dopamine evaluated at various levels of theory. See DOI: 10.1039/c0cp02133d
At physiological $\mathrm{pH}$ values, i.e. at $\mathrm{pH}=7.4$ for human blood, dopamine and other catecholamines occur in their protonated form,,$^{5-7}$ with protonation occurring at the terminal amino group of the alkylamine side chain. In aqueous $\mathrm{pH}$-neutral solutions $(\mathrm{pH}=7)$, experiments and calculations indicate a nearly equal mixture of extended trans and folded gauche conformers of dopamineH ${ }^{+}$(see Fig. 1 and 2 and Ref. 5 and 8 for the definition of gauche and trans). ${ }^{6,9}$ In contrast, calculations for isolated neutral and protonated dopamine demonstrate the energetic preference for the gauche conformation. ${ }^{6,89}$ In the latter case, this is largely due to the favourable interaction of the positively charged ammonium group with the $\pi$ electron system of the aromatic ring ( $\mathrm{NH}-\pi$ interaction). ${ }^{6,9}$ In contrast, the analysis of the crystal structure and IR spectra of neutral dopamine in the condensed phase yields a trans conformation, which is rationalized by the stronger stabilization through solvation when compared to the gauche conformation. ${ }^{10}$ These studies demonstrate that solvation has a strong influence on the preferred conformation of dopamine $\left(\mathrm{H}^{+}\right)$. The conformational flexibility due to rotations about the $\mathrm{C}-\mathrm{N}$ and the two $\mathrm{C}-\mathrm{C}$ bonds of the ethylamine side chain of protonated dopamine is expected to be an important factor for molecular recognition phenomena in drug-receptor interactions. A deeper understanding of these subtle interactions at the molecular level requires the 


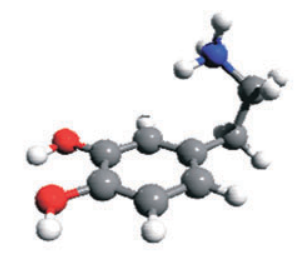

g-1

$\Delta \mathrm{E}$

$\Delta \mathrm{G}$

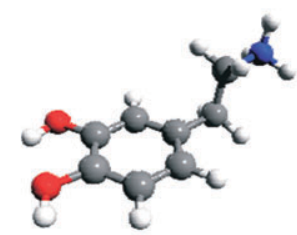

t1

18.5 (22.9)

$16.4(20.7)$

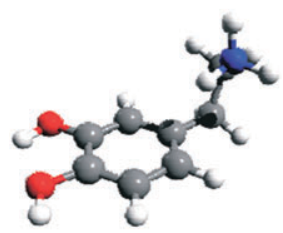

g+1

$0.5(0.5)$

$0.0(0.0)$

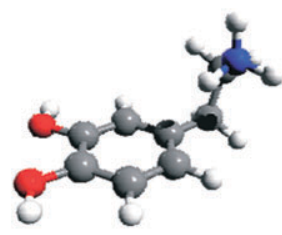

$\mathrm{g}+3$

20.7 (20.7)

20.8 (20.9)

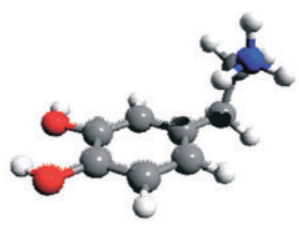

g+2

$4.2(4.3)$

$4.3(4.6)$

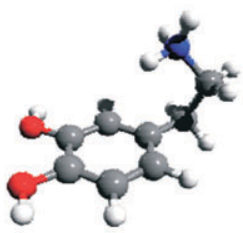

g-3

24.3 (23.6)

23.5 (22.7)

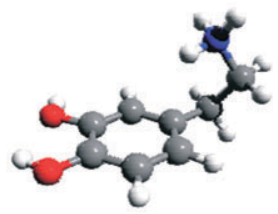

g-2

8.7 (8.1)

$5.4(5.6)$

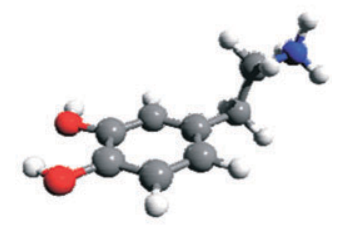

t2

24.6 (29.1)

22.6 (26.7)

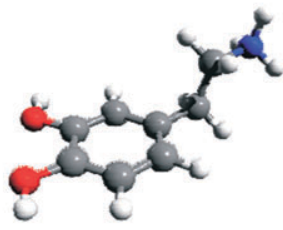

t3

$40.5(45.0)$

$38.3(42.8)$

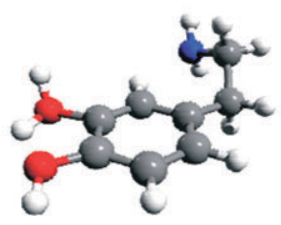

g-1(02)

155.8 (164.6)

$154.9(163.8)$

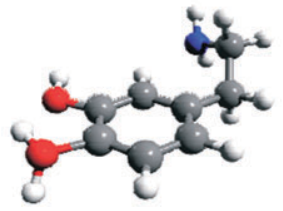

g-2(01)

$157.2(167.1)$

156.5 (166.1)

Fig. 1 Structures and relative energies $\left(\Delta E\right.$, top) and free energies $\left(\Delta G\right.$, bottom) of selected isomers of dopamineH ${ }^{+}$calculated at the $\mathrm{B} 3 \mathrm{LYP} / \mathrm{cc}-\mathrm{pVDZ}$ level. Relative energies obtained at the MP2/cc-pVDZ level are listed in parentheses in $\mathrm{kJ} \mathrm{mol}^{-1}$.

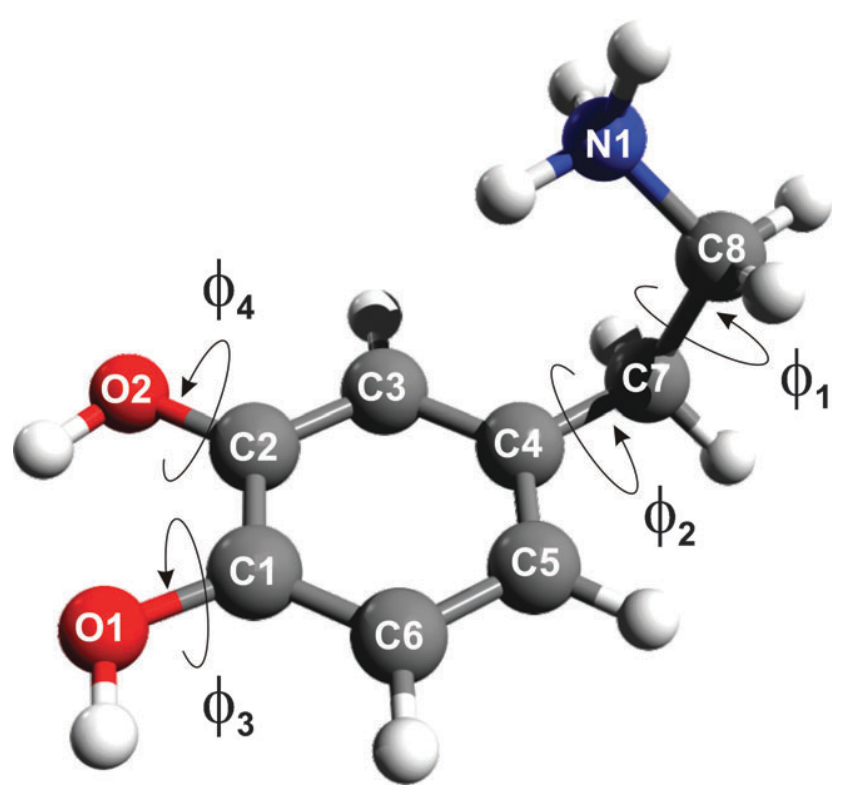

Fig. 2 Torsional angles defining the conformation of the various possible isomers of dopamine ${ }^{+}$. The angles $\phi_{1}$ and $\phi_{2}$ differentiate between gauche $\left(+\right.$ or - ) and trans isomers, whereas $\phi_{3}$ and $\phi_{4}$ describe the relative orientation of the hydroxyl groups leading to a further index 1,2 , or 3 . characterization of possible conformations of isolated catecholamine neurotransmitters and the influence of protonation (charge) and microsolvation on their structure and relative stability. The conformation of dopamine in various environments is not only relevant for physiological processes but also for applications in the fields of spectroscopy and material sciences. For example, Pande et al. measured surface-enhanced Raman spectra of dopamine on bimetallic nanocolloids and report calculations of the bare molecule in different charge states. ${ }^{4}$ Interestingly, their calculated structure for dopamine $\mathrm{H}^{+}$ (t3 in Fig. 1) differs from the lowest-energy isomer identified in the present work ( $\mathbf{g}-\mathbf{1}$ in Fig. 1), suggesting that the conformation of dopamine changes upon adsorption on a bimetallic nanocolloid.

Experimental information on the structure of isolated dopamine $\mathrm{H}^{+}$is restricted to mass spectrometric data, which mainly provide fragmentation pathways observed after collisional activation and thus only very indirect information about the geometry. ${ }^{11,12}$ The facile elimination of $\mathrm{NH}_{3}$ upon collision-induced dissociation ${ }^{11,12}$ is compatible with preferential protonation at the terminal amino group of the ethyl side chain, as predicted by theory. ${ }^{5}$ The proton affinity calculated at the B3LYP/6-31G(d) level amounts to $940 \mathrm{~kJ} \mathrm{~mol}^{-1},{ }^{13}$ however no experimental determination of this quantity appears to be available ${ }^{13-15}$ for comparison to 
confirm the protonation site. Thus, the present IR spectroscopic study of isolated dopamine $\mathrm{H}^{+}$provides the first experimental information about the conformation and protonation site of this fundamental biomolecular species in the gas phase.

Recent pioneering IR spectroscopic studies on protonated neurotransmitters and analogues by Simons and coworkers include ethanolamine $\mathrm{H}^{+}$, ephedrine $\mathrm{H}^{+}$, pseudoephedrine $\mathrm{H}^{+}$, 1-phenylethylamine $\mathrm{H}^{+}$, and 2-amino-1-phenylethanolH ${ }^{+} .{ }^{16}$ In these studies, protonation of the neurotransmitter molecule is accomplished by ionization-induced intracluster proton transfer occurring in a hydrogen-bonded phenol-neurotransmitter cluster generated in a molecular beam. This process yields a phenoxyneurotransmitterH ${ }^{+}$dimer, whose structure is then probed by IR photodissociation spectroscopy monitoring the loss of the phenoxy radical. Alternatively, the neurotransmitter $\mathrm{H}^{+}$can directly be produced upon post-ionization fragmentation and then probed by IR multiple photon dissociation. ${ }^{16}$ Due to the special production mechanism, the inferred protonation site may, however, not necessarily be the energetically most favourable one of the considered isolated neurotransmitter $\mathrm{H}^{+}$, as barriers for proton migration can be substantial in bio-organic molecules. Moreover, this approach is limited to neurotransmitters and other biomoelcules, which can be transferred into the gas phase by thermal heating.

Electrospray ionization (ESI) offers an alternative and rather general route to efficiently generate isolated protonated biomolecules in the gas phase. In particular, IR photodissociation spectroscopy coupled with ESI and tandem mass spectrometry, in combination with quantum chemical calculations, has proven to be an efficient tool to characterize the structure of isolated protonated biomolecules in the gas phase, with the particular focus on the determination of the preferred site of protonation. ${ }^{17,18}$ Alternative techniques to unravel the protonation sites and conformations of protonated biomolecules and their clusters involve IR hole-burning spectroscopy of ESI-prepared ions in cryogenic ion traps. ${ }^{19,20}$ For bare protonated ions, often IR multiple photon dissociation (IRMPD) is required to overcome the high dissociation threshold of these strongly bound ions. The IRMPD process is realized through the successful coupling of tandem mass spectrometers and ion traps with intense IR free electron lasers (IR-FEL) providing tuneable IR radiation in the fingerprint spectral range $\left(50\right.$ to $\left.2500 \mathrm{~cm}^{-1}\right)$. The structures of a plethora of (bio-)organic and metal-organic ions and their complexes have been characterized recently by IRMPD. ${ }^{17,21-23}$ In a recent campaign, ${ }^{24}$ IRMPD spectra of a series of ESI-generated protonated neurotransmitters (dopamine, histamine, serotonin) were recorded in the fingerprint range in a Fourier transform ion cyclotron resonance mass spectrometer (FT-ICR-MS), which was coupled to the IR beamline of the Free Electron Laser for Infrared eXperiments (FELIX). The present work provides a detailed analysis of the IRMPD spectrum of dopamine $\mathrm{H}^{+}$utilizing quantum chemical calculations at the B3LYP and MP2 levels of theory.

\section{Experimental and theoretical techniques}

The IR spectrum of the isolated protonated neurotransmitter dopamine was obtained in the fingerprint range $\left(570-1880 \mathrm{~cm}^{-1}\right)$ by means of IRMPD spectroscopy. The spectrum was recorded in a FT-ICR-MS, equipped with an ESI source and coupled to the IR beamline of FELIX. ${ }^{23,25}$ Dopamine was purchased from Sigma-Aldrich as solid dopamine hydrochloride (dopamine* $\mathrm{HCl}$ ) in analytical reagent grade and used without further purification. Protonated dopamine ions were produced by spraying a solution of dopamine* $\mathrm{HCl}$ dissolved in water/methanol $(1: 4)\left(\sim 2 \times 10^{-5} \mathrm{M}\right)$ at a flow rate of $\sim 10 \mu \mathrm{L} \mathrm{min}{ }^{-1}$ into the ESI source. The produced ions were accumulated in a hexapole ion trap for $4 \mathrm{~s}$ and transferred into the ICR trap via an octopole ion guide. Subsequently, the dopamine $\mathrm{H}^{+}$ions were mass selected in the ion trap and irradiated for $2 \mathrm{~s}$ with 10 macropulses from FELIX operating at a repetition rate of $5 \mathrm{~Hz}$. The average macropulse energy was determined to be $\sim 35 \mathrm{~mJ}$. The bandwidth of the FELIX radiation is of the order of $0.5 \%$ of the central wavelength (FWHM), which corresponds to $5 \mathrm{~cm}^{-1}$ at $1000 \mathrm{~cm}^{-1}$. The calibration of the wavelength was achieved via a grating spectrometer with an accuracy of $\pm 0.02 \mu \mathrm{m}$, corresponding to \pm 0.5 and $\pm 8 \mathrm{~cm}^{-1}$ at frequencies of 500 and $2000 \mathrm{~cm}^{-1}$, respectively. Depending on the laser frequency, the step size varied between 2 and $7 \mathrm{~cm}^{-1}$. The main fragmentation

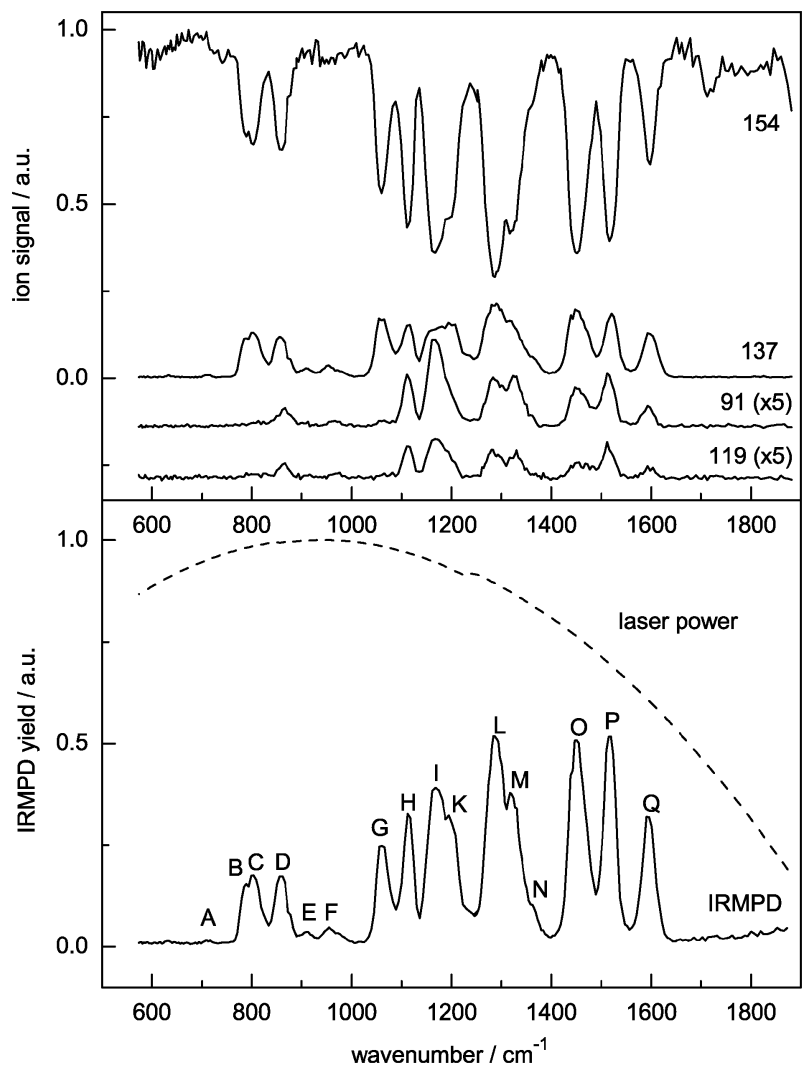

Fig. 3 Upper panel: ion currents of the dopamine $\mathrm{H}^{+}$parent ion $(m=154 \mathrm{u})$ and the three fragment channels with $m=137,119$ and $91 \mathrm{u}$ (the latter are multiplied by 5), corresponding to formal loss of $\mathrm{NH}_{3}$, loss of $\mathrm{NH}_{3}$ and $\mathrm{H}_{2} \mathrm{O}$, and loss of $\mathrm{NH}_{3}, \mathrm{H}_{2} \mathrm{O}$ and $\mathrm{CO}$, respectively, as a function of the IR laser frequency. Lower panel: IRMPD spectrum of dopamine ${ }^{+}$recorded in the fingerprint range. The IRMPD yield is obtained by taking all three fragmentation channels into account and normalizing linearly for IR laser power variations (dashed line). The positions and assignments of the transitions observed $(\mathrm{A}-\mathrm{Q})$ are listed in Table 1. 
channels observed upon IRMPD of protonated dopamine ( $m=154 \mathrm{u}$ ) are $m=137,119$ and $91 \mathrm{u}$, corresponding to sequential loss of $\mathrm{NH}_{3}, \mathrm{H}_{2} \mathrm{O}$ and $\mathrm{CO}$, respectively. Parent and fragment ion intensities are monitored as a function of the laser frequency (Fig. 3), and the IRMPD yield is then calculated as the integrated intensity of the fragment ions divided by the sum of parent and fragment ion intensities, followed by linear normalization for variations in the IR laser power.

Quantum chemical calculations at the B3LYP and MP2 levels of theory using the cc-pVDZ basis set ${ }^{26}$ were performed for protonated dopamine in order to locate various low lying isomers on the potential energy surface and to evaluate their structure, energetics and IR spectral properties. ${ }^{27}$ Energies include harmonic zero point energy corrections, scaled with the respective factors of 0.98 (B3LYP) and 0.97 (MP2). For all minima the frequency analysis ensured their nature as local or global minima on the potential energy surface. Theoretical IR stick spectra are convoluted with a width (FWHM) of

Table 1 Experimental vibrational frequencies of dopamine $\mathrm{H}^{+}$ (IRMPD spectrum, Fig. 5) compared to frequencies of the $\mathbf{g}-\mathbf{1}$ isomer calculated at the B3LYP/cc-pVDZ level

\begin{tabular}{|c|c|c|}
\hline $\begin{array}{l}\text { Dopamine } \mathrm{H}^{+a} \\
\nu_{\text {exp }} / \mathrm{cm}^{-1}\end{array}$ & $\begin{array}{l}\mathbf{g}-\mathbf{1}^{b} \\
\nu_{\text {calc }} / \mathrm{cm}^{-1}\end{array}$ & Vibration $^{c}$ \\
\hline \multirow[t]{4}{*}{1595 (31) Q } & $1631(22)$ & Arom. $\sigma_{\mathrm{CC}}\left(\nu_{8 \mathrm{a}}\right)$ \\
\hline & $1616(59)$ & Arom. $\sigma_{\mathrm{CC}}\left(\nu_{8 \mathrm{~b}}\right)$ \\
\hline & $1598(33)$ & $\beta_{\mathrm{NH}_{3}}$ asym. \\
\hline & $1577(16)$ & $\beta_{\mathrm{NH}_{3}}$ asym. \\
\hline \multirow[t]{2}{*}{$1516(30) \mathrm{P}$} & $1529(205)$ & Arom. $\sigma_{\mathrm{CC}}\left(\nu_{19 \mathrm{~b}}\right)$ \\
\hline & $1470(2)$ & Arom. $\sigma_{\mathrm{CC}}\left(\nu_{19 \mathrm{a}}\right)$ \\
\hline \multirow[t]{3}{*}{$1449(40) \mathrm{O}$} & $1444(42)$ & $\beta_{\mathrm{CH}_{2}}$ (scissoring, C8) \\
\hline & $1433(97)$ & $\beta_{\mathrm{NH}_{3}}$ sym., umbrella \\
\hline & $1424(15)$ & $\beta_{\mathrm{CH}_{3}}$ (scissoring, C7) \\
\hline \multirow[t]{2}{*}{$1358(-) \mathrm{N}$} & $1382(20)$ & Arom. $\sigma_{\mathrm{CC}}$ \\
\hline & $1361(2)$ & $\beta_{\mathrm{CH}_{2}}$ (wagging, C8) \\
\hline \multirow[t]{2}{*}{1319 (31) M } & $1333(146)$ & $\beta_{\mathrm{CH}_{2}}$ (wagging, C7) \\
\hline & $1323(65)$ & $\beta_{\mathrm{COH}}$ (in-phase) \\
\hline \multirow[t]{4}{*}{ 1287(38) L } & $1303(135)$ & $\sigma_{\mathrm{CO}}(\mathrm{C} 1-\mathrm{O} 1)$ \\
\hline & $1288(45)$ & $\tau_{\mathrm{CH}_{2}}($ torsion, $\mathrm{C} 8)$ \\
\hline & $1275(27)$ & $\sigma_{\mathrm{CO}}(\mathrm{C} 2-\mathrm{O} 2)$ \\
\hline & $1221(3)$ & $\tau_{\mathrm{CH}_{2}}($ torsion, $\mathrm{C} 7)$ \\
\hline $1197(33) \mathrm{K}$ & $1187(54)$ & $\beta_{\mathrm{COH}}$ (out-of-phase) \\
\hline \multirow[t]{2}{*}{$1166(40) \mathrm{I}$} & $1154(71)$ & Arom. $\beta_{\mathrm{CH}}(\mathrm{C} 3)$ \\
\hline & $1146(34)$ & Arom. $\beta_{\mathrm{CH}}(\mathrm{C} 5 / \mathrm{C} 6)$ \\
\hline $1114(27) \mathrm{H}$ & $1110(82)$ & Arom. $\beta_{\mathrm{CH}}(\mathrm{C} 5 / \mathrm{C} 6)$ \\
\hline \multirow{2}{*}{$1060(33) \mathrm{G}$} & $1062(2)$ & $\mathrm{CH}_{2}$ twist $\left(\mathrm{CH}_{2} / \mathrm{CH}_{2} / \mathrm{NH}_{3}\right)$ \\
\hline & $1046(64)$ & $\mathrm{CH}_{2}$ twist $\left(\mathrm{CH}_{2} / \mathrm{CH}_{2} / \mathrm{NH}_{3}\right)$ \\
\hline \multirow[t]{2}{*}{$959(50) \mathrm{F}$} & $964(5)$ & Aliph. $\sigma_{\mathrm{CCN}}(\mathrm{C} 7-\mathrm{C} 8-\mathrm{N} 1)$ \\
\hline & $949(21)$ & Aliph. $\sigma_{\mathrm{CCN}}(\mathrm{C} 7-\mathrm{C} 8-\mathrm{N} 1)$ \\
\hline \multirow[t]{2}{*}{909 (36) E } & $920(2)$ & Arom. $\gamma_{\mathrm{CH}}(\mathrm{C} 5 / \mathrm{C} 6)$ \\
\hline & $899(10)$ & $\mathrm{CH}_{2}$ twist $\left(\mathrm{CH}_{2} / \mathrm{CH}_{2} / \mathrm{NH}_{3}\right)$ \\
\hline \multirow[t]{3}{*}{858 (31) D } & $851(38)$ & Arom. $\gamma_{\mathrm{CH}}(\mathrm{C} 3)$ \\
\hline & $844(18)$ & $\sigma_{\mathrm{CN}}$ \\
\hline & $816(6)$ & Arom. $\gamma_{\mathrm{CH}}(\mathrm{C} 5 / \mathrm{C} 6)$ \\
\hline $802(22) \mathrm{C}$ & $802(16)$ & Delocalized $^{d}$ \\
\hline \multirow[t]{2}{*}{$786(22) \mathrm{B}$} & $780(16)$ & Ring $\left(\nu_{1}\right)$ \\
\hline & $725(1)$ & Arom. $\gamma_{\mathrm{CC}}\left(\nu_{4}\right)$ \\
\hline $712(20) \mathrm{A}$ & $702(9)$ & $\operatorname{Ring}\left(\nu_{12}\right)$ \\
\hline
\end{tabular}

${ }^{a}$ Widths (in $\mathrm{cm}^{-1}$ ) of the transitions are given in parentheses (see Fig. 5 for labels of the transitions). ${ }^{b}$ IR intensities in $\mathrm{km} \mathrm{mol}^{-1}$ are given in parentheses. ${ }^{c}$ The nomenclature for the modes of the aromatic ring is adopted from the Wilson notation for substituted benzene derivatives. ${ }^{33}$ The notation $\sigma, \gamma, \beta$, and $\tau$ is used to designate stretch, out-of-plane bend, in-plane bend, and torsional motions, respectively. ${ }^{d}$ Strongly coupled mode involving aromatic $\gamma_{\mathrm{CH}}$ and alkyl twist, torsion, and stretch motions.
$30 \mathrm{~cm}^{-1}$ in order to facilitate convenient comparison with the experimental spectrum. The charge distribution was analyzed using the natural bond orbital (NBO) population analysis.

\section{Results and discussion}

\subsection{IRMPD spectrum and assignment}

The IRMPD spectrum of protonated dopamine shown in Fig. 3 is rich in structure and reveals 16 distinct bands, labelled A-Q, in the $570-1880 \mathrm{~cm}^{-1}$ spectral range (Table 1). As mentioned, the IRMPD spectrum was obtained by monitoring the three fragment channels with $m=137,119$ and $91 \mathrm{u}$. The depletion spectrum of the parent ion $(m=154 \mathrm{u})$ is also shown in Fig. 3, along with the appearance spectra observed in the three individual daughter ion channels. The $m=137 \mathrm{u}$ daughter ion is the dominant fragment ion and is generated by elimination of $\mathrm{NH}_{3}$. There are several candidates for the structure of the $137 \mathrm{u}$ ion (vide infra). The $119 \mathrm{u}$ daughter ions correspond to formal loss of $\mathrm{NH}_{3}$ and $\mathrm{H}_{2} \mathrm{O}$, while the $91 \mathrm{u}$ daughter ions correspond to formal loss of $\mathrm{NH}_{3}$, $\mathrm{H}_{2} \mathrm{O}$, and $\mathrm{CO}$. The spectra monitored in these daughter channels are much weaker than that detected in the $137 \mathrm{u}$ channel (by a factor of $\sim 5$ for strong resonances). Moreover, their spectral appearance differs significantly from the one observed in the $137 \mathrm{u}$ mass channel. This observation is consistent with secondary IR absorption ${ }^{28}$ and dissociation of the primary $137 \mathrm{u}$ daughter ions. Thus, the bands in the 119 and $91 \mathrm{u}$ channels occur only at resonances of both the $154 \mathrm{u}$ parent ions and the $137 \mathrm{u}$ primary fragment ions. The IRMPD yield obtained by taking into account all fragment channels shows good correspondence with the depletion signal of the parent ion channel. However, it displays better signal-to-noise ratio because it is normalized for variations of the parent ion production in the ESI source. Thus, the IRMPD spectrum will be compared to the calculated spectra. The depletion of the parent ion signals exceeds $50 \%$ at the strongest resonances indicating efficient IRMPD. The widths of the IRMPD bands are of the order of $30 \mathrm{~cm}^{-1}$ and arise from several factors, including the finite laser bandwidth of $0.5 \%$ (corresponding to $\Delta \nu=2.5-7.5 \mathrm{~cm}^{-1}$ for $\left.\nu=500-1500 \mathrm{~cm}^{-1}\right)$, unresolved rotational structure $(T=300 \mathrm{~K}$ for ions in the ICR cell), spectral congestion due to overlapping vibrational transitions, spectral broadening arising from the multiple photonic character of the IRMPD process, and the resulting heating of the ions during the long irradiation time. ${ }^{22}$

In order to establish the vibrational and isomer assignment of the transitions observed in the IRMPD spectrum, quantum chemical calculations were performed. In agreement with previous calculations, ${ }^{5}$ the extensive search on the potential energy surface of dopamine ${ }^{+}$yielded several low-lying minima for protonation at the $\mathrm{N}$ atom of the terminal amino group. In total, nine isomers were identified at both the B3LYP and the MP2 levels in the energy range below $50 \mathrm{~kJ} \mathrm{~mol}^{-1}$ (Fig. 1). The atom numbering and relevant angular coordinates used to describe the isomeric structures are shown in Fig. 2. The nomenclature for the isomers is adopted from the one used by Park et al. for neutral dopamine. ${ }^{8}$ The notation $\mathbf{g}$ and $\mathbf{t}$ describes isomers, in which the ammonium group is oriented in 
gauche or trans orientation with respect to the aromatic ring. In the $\mathbf{g}$ isomers the ammonium group is pointing toward the ring $\left(-90^{\circ}<\phi_{1}<90^{\circ}\right)$, while in the $\mathbf{t}$ isomers it points away from it $\left(\phi_{1}>90^{\circ}\right.$ or $\left.\phi_{1}<-90^{\circ}\right)$. The gauche isomers are further divided into those with positive and negative $\phi_{1}$ values, as indicated by $\mathbf{g}+$ and $\mathbf{g}-$, respectively. All gauche and trans isomers can further be classified by the orientation of the two hydroxyl groups, described by $\phi_{3}$ and $\phi_{4}$. The notation 1 and 2 describes isomers, in which both $\mathrm{OH}$ groups of the nearly planar catechol unit are oriented in the same direction, leading to the formation of an intramolecular $\mathrm{OH}$... O hydrogen bond. ${ }^{29,30}$ Isomers 3 have a coplanar $\mathrm{H}-\mathrm{O} \cdots \mathrm{O}-\mathrm{H}$ orientation of the hydroxyl groups. Conformers which are mirror images of the discussed structures in Fig. 1 are not considered further, because they are symmetry-equivalent and have the same properties. ${ }^{30}$ Furthermore, energetically less stable isomers with a non-coplanar $\mathrm{O}-\mathrm{H} \cdots \mathrm{O}-\mathrm{H}$ configuration with respect to the aromatic plane or with the unfavourable $\mathrm{O}-\mathrm{H} \cdots \mathrm{H}-\mathrm{O}$ motif are also not discussed further.

In general, there is good agreement between the relative energies $(\Delta E)$ and free energies $(\Delta G)$ and the energetic order of the isomers calculated at the B3LYP and MP2 levels of theory (Fig. 1). For example, for the four lowest-energy structures lying below $10 \mathrm{~kJ} \mathrm{~mol}^{-1}$, the agreement is better than $0.6 \mathrm{~kJ} \mathrm{~mol}^{-1}$. Both levels predict the $\mathbf{g}-\mathbf{1}$ isomer to be the global minimum on the potential, with only a small energy gap of $0.5 \mathrm{~kJ} \mathrm{~mol}^{-1}$ to the related $\mathbf{g}+\mathbf{1}$ isomer. However, the small energetic preference for $\mathbf{g}-\mathbf{1}$ over $\mathbf{g}+\mathbf{1}$ is reversed when considering the free energies $(\Delta G)$ calculated at room temperature. Both nearly isoenergetic isomers are separated by an appreciable barrier of $13 \mathrm{~kJ} \mathrm{~mol}^{-1}$ (B3LYP). The g2 isomers are slightly less stable than the $\mathbf{g} \mathbf{1}$ isomers by 4-9 $\mathrm{kJ} \mathrm{mol}^{-1}$. As a general trend, the $\mathbf{t}$ isomers are energetically less favourable than the corresponding $\mathbf{g}$ isomers by $\sim 20 \mathrm{~kJ} \mathrm{~mol}^{-1}$, as they lack the intramolecular $\mathrm{NH}-\pi$ interaction of the ammonium group with the aromatic ring. Moreover, the $\mathbf{t}$ isomers are well separated from the g isomers by significant internal rotation barriers, e.g. $V=14 \mathrm{~kJ} \mathrm{~mol}^{-1}$ for $\mathbf{t} \mathbf{1} \rightarrow \mathbf{g}-\mathbf{1}$ (B3LYP). Similarly, the $\mathbf{3}$ isomers are less stable by around $20 \mathrm{~kJ} \mathrm{~mol}^{-1}$ than the $\mathbf{1}$ and $\mathbf{2}$ isomers, because they lack the intramolecular hydrogen bonds between the $\mathrm{OH}$ groups. For further comparison, also a few structures were calculated with protonation at the hydroxyl groups. However, they are more than $150 \mathrm{~kJ} \mathrm{~mol}^{-1}$ less stable than the N-protonated species, as shown for the $\mathbf{g - 1 ( O 2 )}$ and g-2(O1) isomers in Fig. 1. Protonation of primary amines at the N-side is clearly favoured in the gas phase. ${ }^{5,9}$

Although there is in general good agreement between the relative energies of the various isomers calculated at the MP2 and B3LYP levels, there is a systematically larger energy difference between corresponding $\mathbf{g}$ and $\mathbf{t}$ isomers at the MP2 level. For example, the relative energies of the $\mathbf{t} \mathbf{1}-\mathbf{t} \mathbf{3}$ isomers are higher by $4.5 \mathrm{~kJ} \mathrm{~mol}^{-1}$ at the MP2 level than at the B3LYP level. This additional relative stabilization of the $\mathbf{g}$ isomers with respect to the $\mathbf{t}$ isomers at the MP2 level is attributed to dispersion interactions of the ammonium group with the aromatic ring, which are relevant only for the $\mathbf{g}$ isomers and are neglected in the B3LYP calculations. These additional dispersion forces of the intramolecular $\mathrm{NH}-\pi$ bond also lead
Table 2 Selected bond distances (in $\AA$ ), dihedral angles (in degrees), and relative energies and free energies at $298 \mathrm{~K}_{\text {(in kJ mol}}^{-1}$ ) of the protonated dopamine isomers $\mathbf{g}-\mathbf{1}, \mathbf{g}+\mathbf{1}$ and $\mathbf{t} \mathbf{1}$ calculated at the B3LYP and MP2 levels (Fig. 1 and 2) ${ }^{a}$

\begin{tabular}{|c|c|c|c|c|c|c|}
\hline & \multicolumn{2}{|l|}{$\underline{g-1}$} & \multicolumn{2}{|l|}{$g+1$} & \multicolumn{2}{|l|}{ t1 } \\
\hline & B3LYP & MP2 & B3LYP & MP2 & B3LYP & MP2 \\
\hline$\phi_{1}$ & -54.7 & -54.0 & 54.7 & 53.3 & -178.4 & -178.7 \\
\hline$\phi_{2}$ & -84.9 & -81.3 & -98.5 & -101.6 & -97.0 & -95.1 \\
\hline$\phi_{3}$ & 177.1 & 176.7 & 177.5 & 177.1 & 178.7 & 178.3 \\
\hline$\phi_{4}$ & 174.4 & 173.1 & 174.5 & 173.0 & 177.7 & 176.6 \\
\hline $\mathrm{R}_{\mathrm{NH}} \cdots \mathrm{C} 3$ & 2.340 & 2.304 & 2.422 & 2.414 & & \\
\hline $\mathrm{R}_{\mathrm{NH} \cdots \mathrm{C} 4}$ & 2.376 & 2.303 & 2.339 & 2.264 & & \\
\hline $\mathrm{R}_{\mathrm{OH} \cdots \mathrm{OH}}$ & 2.133 & 2.122 & 2.125 & 2.114 & 2.127 & 2.114 \\
\hline$\Delta E$ & 0.0 & 0.0 & 0.5 & 0.5 & 18.5 & 22.9 \\
\hline$\Delta G$ & 0.1 & 0.2 & 0.0 & 0.0 & 16.4 & 20.7 \\
\hline
\end{tabular}

to a shorter distance between the proton donor of the ammonium group and the aromatic ring at the MP2 level (by $\sim 0.07 \AA$ ). In order to verify that the additional stabilization of $4.5 \mathrm{~kJ} \mathrm{~mol}^{-1}$ for the $\mathrm{g}$ isomers at the MP2 level is indeed due to dispersion and not due to intramolecular basis set superposition error, ${ }^{31}$ calculations were performed at the B3LYP and B3LYP-D levels (cc-pVDZ basis). Again, the energy differences between the $\mathbf{g}$ and $\mathbf{t}$ isomers obtained at the B3LYP-D level (which includes dispersion) are 5-6 $\mathrm{kJ} \mathrm{mol}^{-1}$ larger than those obtained at the B3LYP level (neglecting dispersion). Comparison between the B2PLYP and B2PLYP-D levels shows that the effects of dispersion are $\sim 3 \mathrm{~kJ} \mathrm{~mol}^{-1}$, in line with calculations at the M06-2X level (Table $\mathrm{S} 1$ in ESI $\dagger$ ). Thus, these additional calculations suggest that the higher stabilization of the $\mathbf{g}$ isomers observed at the MP2 level as compared to the B3LYP level are not due to effects of basis set superposition error in folded conformers. ${ }^{31}$ Moreover, they also indicate that the dispersion forces are not severely overestimated at the MP2 level for the present system, ${ }^{32}$ as they are similar at the DFT-D levels.

Selected structural and energetic parameters for the most stable gauche and trans isomers of dopamine $\mathrm{H}^{+}, \mathbf{g}-\mathbf{1}, \mathbf{g}+\mathbf{1}$, and $\mathbf{t} \mathbf{1}$, are summarized in Table 2. The table lists the important dihedral angles describing the conformation of the alkyl side chain and the $\mathrm{OH}$ groups with respect to the aromatic ring $\left(\phi_{1}-\phi_{4}\right)$ and the lengths of the intramolecular hydrogen bonds. Corresponding data for all calculated isomers can be found in $\mathrm{ESI} \dagger$ (Table S2). The global minimum $\mathbf{g}-\mathbf{1}$ is stabilized by the interaction between the positively charged ammonium group and the aromatic ring, which is characterized by intramolecular $\mathrm{NH}-\mathrm{C} 3$ and $\mathrm{NH}-\mathrm{C} 4$ bond lengths of 2.3-2.4 $\AA$. For the g-1 isomer of neutral dopamine, $\mathbf{g - 1 ( n ) , ~ t h i s ~ i n t r a m o l e c u l a r ~}$ interaction is substantially weaker, with $\mathrm{NH}-\mathrm{C} 3$ and $\mathrm{NH}-\mathrm{C} 4$ bond lengths of $2.8 \AA$, confirming the additional chargeenhanced attraction between the amino group and the aromatic ring upon protonation. The strong intramolecular $\mathrm{NH}-\pi$ interaction is also visible in the substantial elongation of the $\mathrm{N}-\mathrm{H}$ bond of the proton donor as compared to the length of the free $\mathrm{N}-\mathrm{H}$ bonds (by $0.014 \AA$ at the B3LYP level).

Fig. 4 compares the experimental IRMPD spectrum of dopamine $\mathrm{H}^{+}$with those of all considered isomers calculated at the B3LYP level. Although this comparison does not allow 


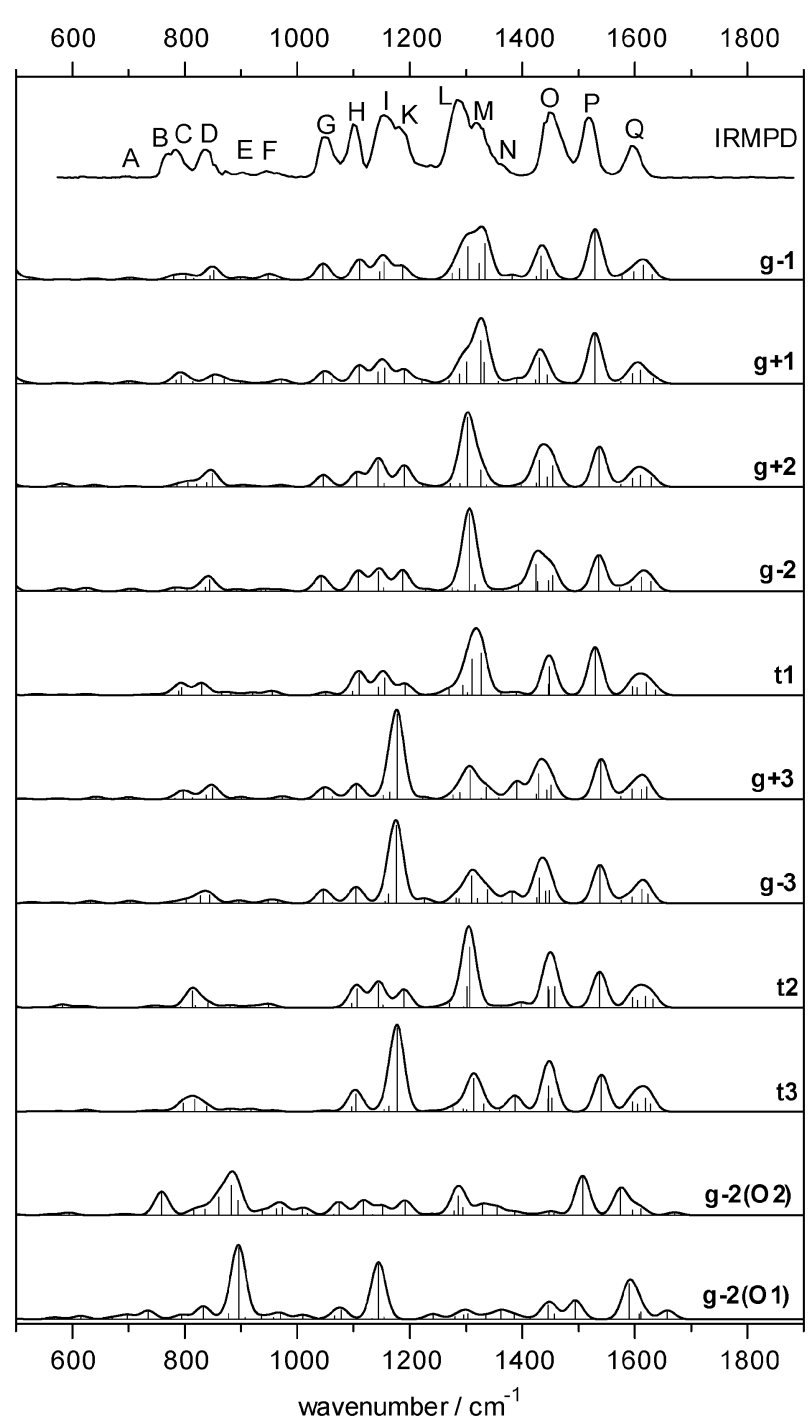

Fig. 4 IRMPD spectrum of dopamine $\mathrm{H}^{+}$and linear IR absorption spectra of various isomers evaluated at the $\mathrm{B} 3 \mathrm{LYP} / \mathrm{cc}-\mathrm{pVDZ}$ level (scaling factor 0.98 , convolution width of FWHM $=30 \mathrm{~cm}^{-1}$ ). The calculated spectra are sorted with increasing energy of the isomers (Fig. 1). The calculated intensities are drawn to the same scale.

for an unambiguous assignment of the spectrum to a single isomer, several conclusions can be drawn. First, when considering the integral of the difference spectra, the best agreement between experiment and theory is observed for the lowest-energy isomer, $\mathbf{g}-\mathbf{1}$. However, further contributions to the IRMPD spectrum from the low-lying $\mathbf{g}+\mathbf{1}, \mathbf{g}+\mathbf{2}$, and $\mathbf{g - 2}$ isomers cannot be ruled out spectroscopically. In fact, as these are calculated to be within $9 \mathrm{~kJ} \mathrm{~mol}^{-1}$ of the global minimum, some contributions of these isomers to the IRMPD spectrum recorded at room temperature are expected. In particular, the $\mathbf{g}+\mathbf{1}$ isomer is only $0.5 \mathrm{~kJ} \mathrm{~mol}^{-1}$ less stable than $\mathbf{g}-\mathbf{1}$, which suggests a significant population in the sampled dopamine $\mathrm{H}^{+}$ ion cloud assuming thermodynamic equilibrium. The relatively high intensity of transition L in the IRMPD spectrum may be indicative of a significant population of the $\mathbf{g}+\mathbf{2}$ and $\mathbf{g}-\mathbf{2}$ isomers. But such an enhancement of the lower-frequency band of intense close lying transitions may also be due to the IRMPD process $^{22}$ and thus not necessarily point toward a considerable population of the $\mathbf{g}+\mathbf{2}$ and $\mathbf{g}-\mathbf{2}$ isomers. Second, the observation of the relatively intense band $G$ in the IRMPD spectrum allows for an exclusion of all $\mathbf{t}$ isomers as major carriers of the experimental spectrum. None of the calculated spectra of these isomers display an intense feature in this spectral range (attributed to a $\mathrm{CH}_{2}$ twist mode of the alkyl chain). Third, also the $\mathbf{3}$ isomers ( $\mathbf{g} \mathbf{3}$ and $\mathbf{t 3}$ ) can be excluded as major carriers, because their calculated spectra predict the most intense band just below $1200 \mathrm{~cm}^{-1}$, in disagreement with the experimental spectrum. This intense and isolated transition arising from the symmetric $\mathrm{COH}$ bending mode $\left(\beta_{\mathrm{COH}}\right)$ is characteristic for the $\mathbf{3}$ isomers, which do not have the intramolecular $\mathrm{OH}$. . O hydrogen bond. This observation implies that the dopamine $\mathrm{H}^{+}$isomers observed by IRMPD feature an intramolecular H-bond. Finally, also the spectra predicted for the O-protonated isomers are rather different in appearance than the experimental spectrum, with respect to both band positions and band intensities. For example, band $\mathrm{P}$ observed in the experimental spectrum is not reproduced by the calculated spectra of the $\mathbf{g - 1}(\mathbf{O 2})$ and $\mathbf{g - 2 ( O 1 )}$ isomers. Moreover, these isomers have very intense absorptions around $900 \mathrm{~cm}^{-1}$, in disagreement with the experimental IRMPD spectrum. In conclusion, the IRMPD spectrum is compatible with the occurrence of the four lowest-energy isomers, namely $\mathbf{g}-\mathbf{1}, \mathbf{g}+\mathbf{1}, \mathbf{g}+\mathbf{2}$, and $\mathbf{g}-\mathbf{2}$. Assuming thermal equilibrium at $300 \mathrm{~K}$, their relative energies $\Delta E(\Delta G)$ calculated at the B3LYP level suggest a population ratio of $1.0: 0.82: 0.19: 0.03$ ( $0.96: 1.0: 0.16: 0.11)$ for these four isomers, indicating that nearly all population of the dopamine $\mathrm{H}^{+}$ions is roughly equally distributed over the $\mathbf{g}-\mathbf{1}$ and $\mathbf{g}+\mathbf{1}$ isomers, consistent with the experimental IRMPD spectrum. These two isomers have very similar geometrical structures, energies, and IR spectral properties, and can thus not be distinguished by the present spectroscopic approach.

For the following discussion of the vibrational assignments, we will refer to isomer $\mathbf{g}-\mathbf{1}$, because it is believed to be one of the two dominant carriers of the experimental IRMPD spectrum. The slightly less stable and probably also relatively abundant $\mathbf{g}+\mathbf{1}$ isomer has essentially the same IR spectrum as $\mathbf{g} \mathbf{- 1}$, and thus all conclusions concerning vibrational properties apply to both isomers. Table 1 lists the vibrational frequencies and IR intensities of the $\mathbf{g}-\mathbf{1}$ isomer evaluated at the B3LYP level in the spectral range of the recorded IRMPD spectrum of dopamine $\mathrm{H}^{+}$, and a direct comparison of the two spectra is presented in Fig. 4. The nomenclature for the modes of the aromatic ring is adopted from the Wilson notation for substituted benzene derivatives. ${ }^{33}$ Several bands in the IRMPD spectrum correspond to single isolated transitions (e.g., bands $\mathrm{B}$, C, E, F, G, H, K, P), whereas in other cases the experimental bands are due to more than one vibrational transition. In general, the deviations of the positions of the experimental band maxima from the frequencies of the most intense mode contributing to the band are less than $24 \mathrm{~cm}^{-1}$ (with an average value of $11 \mathrm{~cm}^{-1}$ ), confirming the vibrational and isomer assignments. In addition, all transitions with calculated IR oscillator strengths larger than $\sim 10 \mathrm{~km} \mathrm{~mol}^{-1}$ appear in the IRMPD spectrum, demonstrating efficient IRMPD even for relatively weak transitions. This is consistent with the relatively low energy required for dissociation on the ground electronic state (see $\mathrm{ESI} \dagger$ ). 


\subsection{Effect of protonation}

It is instructive to compare the properties of neutral dopamine with those of dopamine $\mathrm{H}^{+}$in order to establish the effects of protonation on its geometric and electronic structure. This is, however, only possible from the quantum chemical point of view, because the conformation of isolated dopamine has not been characterized experimentally. Calculations predict an energetic preference for gauche isomers for both neutral and protonated dopamine, because they are stabilized through the intramolecular $\mathrm{NH}-\pi$ interaction with the aromatic ring. In the condensed phase, the preferential configuration of (protonated) dopamine changes due to the effects of the environment. The interaction with solvent molecules and counter ions (e.g., in studies of dopamine* $\mathrm{HCl}$ ) is often stronger than the intramolecular $\mathrm{NH}-\pi$ interaction and leads in general to a preferential stabilization of trans conformers, ${ }^{10}$ although the gauche isomers are clearly calculated to be the global minima on the potential of the isolated species.

Owing to the above complications, we restrict ourselves to the comparison of the most stable gauche structures of dopamine $\left(\mathrm{H}^{+}\right)$as obtained by the quantum chemical calculations (Fig. S1 in ESI $\dagger$ ). The energy difference between both structures corresponds to the proton affinity of 954.2 (957.8) $\mathrm{kJ} \mathrm{mol}^{-1}$ at the B3LYP(MP2)/cc-pVDZ level. These values are similar to the previous result of $940 \mathrm{~kJ} \mathrm{~mol}^{-1}$ obtained at the B3LYP/6-31G(d) level, ${ }^{13}$ although the individual conformations were not specified. No experimental value appears to be available for comparison. As already mentioned, protonation drastically enhances the strength of the intramolecular $\mathrm{NH}-\pi$ interaction leading to substantially shorter contacts between the NH proton and the aromatic carbon atoms. As expected, protonation at the $\mathrm{N}$-terminus also leads to an elongation of the $\mathrm{N}-\mathrm{H}$ bonds and a contraction of the neighboring $\mathrm{N}-\mathrm{C}$ bond. All other bond length changes are less significant.

The NBO population analysis of the most stable gauche isomers of dopamine and dopamine $\mathrm{H}^{+}, \mathbf{g - 1 ( n )}$ and $\mathbf{g - 1}$, is detailed in Fig. S2 in ESI. $\dagger$ As expected, the ethylamine side chain carries only little charge $(-0.01 \mathrm{e}, \mathrm{B} 3 \mathrm{LYP})$ in neutral dopamine and nearly the total positive charge $(+0.99$ e) in protonated dopamine. The latter one is mainly localized on the ammonium group $(+0.61 \mathrm{e})$ and to lesser extent in the adjacent $\mathrm{CH}_{2}$ units $(+0.33$ and $+0.05 \mathrm{e})$. The charge on the aromatic ring is not affected upon protonation, consistent with the lack of hyperconjugation in aromatic alkanes. The large positive partial charge on the $\mathrm{NH}_{3}{ }^{+}$group is responsible for the charge-enhanced $\mathrm{NH}-\pi$ interaction in $\mathbf{g} \mathbf{- 1}$.

The structural changes induced by protonation of dopamine translate directly into the vibrational properties and the corresponding IR spectrum. The IR spectra of the most stable gauche isomers of dopamine $\left(\mathrm{H}^{+}\right), \mathbf{g}-\mathbf{1}(\mathbf{n})$ and $\mathbf{g - 1}$, calculated at the B3LYP level are compared in Fig. 5, and the corresponding frequencies are listed in Table S3 in ESI. $\dagger$ As expected, the $\mathrm{N}-\mathrm{H}$ bend modes experience the most drastic influence of protonation in the frequency range investigated. All three $\mathrm{N}-\mathrm{H}$ bend fundamentals have much larger IR intensities for the protonated species due to the large positive partial charge localized on the $\mathrm{NH}_{3}{ }^{+}$group. In particular, the

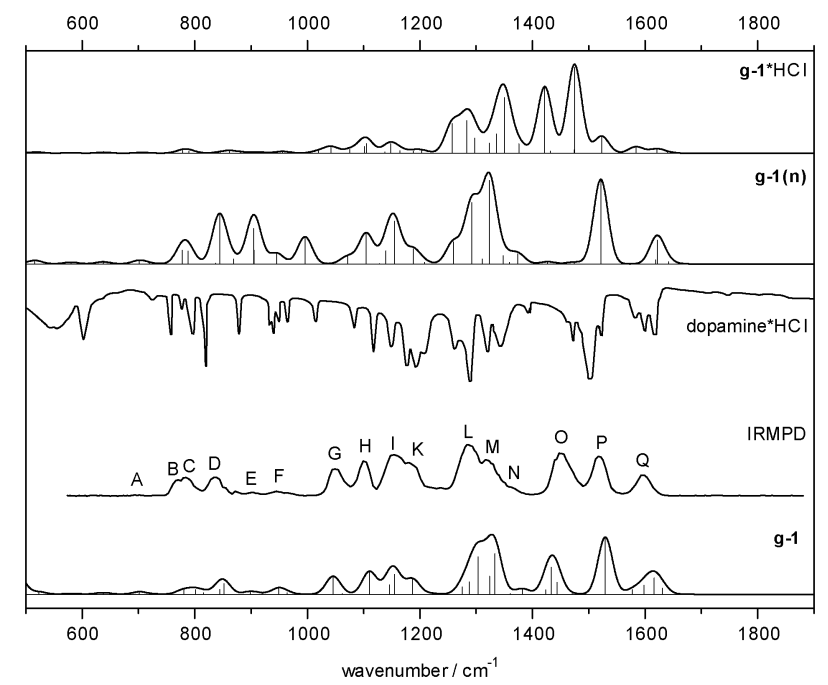

Fig. 5 Comparison of the IRMPD spectrum of dopamineH ${ }^{+}$with the experimental IR spectrum of dopamine* $\mathrm{HCl}$ (NIST database) and IR spectra calculated for the most stable gauche isomers of dopamine ${ }^{+}$, $\mathbf{g - 1}$, neutral dopamine, $\mathbf{g}-\mathbf{1}(\mathbf{n})$, and $\mathbf{g}-\mathbf{1} * \mathrm{HCl}$ calculated at the B3LYP/cc-pVDZ level.

intense symmetric $\mathrm{N}-\mathrm{H}$ umbrella mode at $1433 \mathrm{~cm}^{-1}$ is characteristic for the charged $\mathbf{g}-\mathbf{1}$ species (band $\mathrm{O}$ ), whereas the spectrum of the neutral $\mathbf{g - 1}$ (n) molecule has no intense absorption in this spectral range. Other modes with large frequency shifts and changes in IR intensities are the aliphatic $\mathrm{C}-\mathrm{C}$ and $\mathrm{C}-\mathrm{N}$ stretch modes and the $\mathrm{CH}_{2}$ torsions of the alkylamine side chain occurring in the $800-1300 \mathrm{~cm}^{-1}$ range.

Fig. 5 also includes the IR spectrum of dopamine* $\mathrm{HCl}$ recorded in Nujol/Fluorolube films ${ }^{15}$ taken from the NIST database. ${ }^{15}$ A priori, it is unclear whether this spectrum is due to trans and/or gauche isomers of neutral dopamine (weakly perturbed by hydrogen bonding to $\mathrm{HCl}$ ) or the corresponding zwitterionic form, dopamine $\mathrm{H}^{+}-\mathrm{Cl}^{-}$, or an intermediate species. Overall, there is good agreement between the experimental NIST spectrum and that calculated for $\mathbf{g}-\mathbf{1 ( n )}$. In particular, both spectra lack the $\mathrm{NH}_{3}{ }^{+}$umbrella band near $1430 \mathrm{~cm}^{-1}$ characteristic for the protonated species, suggesting the NIST spectrum resembles more closely that of a neutral dopamine species. Interestingly, the spectrum calculated for isolated $\mathbf{g}-\mathbf{1} * \mathrm{HCl}$ (also shown in Fig. 5) features the intense $\mathrm{NH}_{3}{ }^{+}$umbrella band, indicative of (at least partial) proton transfer from $\mathrm{HCl}$ via hydrogen-bonding to the amino group, eventually leading to the zwitterionic dopamine $\mathrm{H}^{+}-\mathrm{Cl}^{-}$form. Indeed, the calculated $\mathbf{g - 1} * \mathrm{HCl}$ is similar in appearance as the experimental and theoretical IR spectrum of dopamine $\mathrm{H}^{+}$. Thus, apparently the proton transfer within dopamine* $\mathrm{HCl}$ seems to be largely suppressed in Nujol/Fluorolube films. ${ }^{15}$

\subsection{Fragmentation process}

The IRMPD fragments of dopamine ${ }^{+}$observed in the present study are $m=137,119$ and $91 \mathrm{u}$, corresponding to the formal loss of $\mathrm{NH}_{3}(137 \mathrm{u}), \mathrm{NH}_{3}$ and $\mathrm{H}_{2} \mathrm{O}(119 \mathrm{u})$ and $\mathrm{NH}_{3}, \mathrm{H}_{2} \mathrm{O}$ and $\mathrm{CO}(91 \mathrm{u})$, respectively. The photo-induced fragments with $m=137$ and $91 \mathrm{u}$ are also detected in liquid chromatography/tandem mass spectrometry experiments for collision-induced dissociation at 5 and $15 \mathrm{eV}$ collision 
energy. ${ }^{11,12}$ However, the fragment with $m=119 \mathrm{u}$ was only observed in the CID spectra at $35 \mathrm{eV}$ collision energy. ${ }^{11} \mathrm{As}$ outlined above, the analysis of the IR action spectra monitored in the 137 and $91 / 119 \mathrm{u}$ fragment channels indicates that photoinduced fragmentation occurs in a sequential fashion (i.e., $154 \mathrm{u} \rightarrow 137 \mathrm{u} \rightarrow$ 91/119 u). A similar process was recently observed for IRMPD of protonated benzaldehyde. ${ }^{28}$ If IRMPD would lead to fragmentation into competing channels (e.g., $154 \mathrm{u} \rightarrow 137 \mathrm{u}$ and $154 \mathrm{u} \rightarrow 91 \mathrm{u}$ ), the action spectra would be similar in appearance, in case the activation energies do not differ significantly. However, as some intense bands observed in the $137 \mathrm{u}$ channel are almost completely suppressed in the $119 \mathrm{u}$ and $91 \mathrm{u}$ channels, the process must involve sequential photodissociation. As the absorption spectrum of the primary $137 \mathrm{u}$ photofragment is apparently different from that of the $154 \mathrm{u}$ parent ion, bands in the 119 and $91 \mathrm{u}$ channels only show up when both the 154 and $137 \mathrm{u}$ ions resonantly absorb at the considered IR frequency. Significantly, several of the bands with reduced intensity in the 119 and $91 \mathrm{u}$ channels involve motions of the $\mathrm{NH}_{3}$ group (Fig. 3 and Fig. S4 in ESI $\dagger$ ), which spectroscopically confirms that the $137 \mathrm{u}$ fragment is indeed arising from elimination of the terminal $\mathrm{NH}_{3}$ group of dopamine $\mathrm{H}^{+}$. This observation provides further evidence that protonation occurs indeed at the terminal amino group.

In an effort to identify the structure of the fragment ion with $m=137 \mathrm{u}$, several prospective candidates (FI-FIII) are considered in Fig. S3 in ESI. $\dagger$ These ions are found after cutting off the $\mathrm{NH}_{3}$ fragment from various low-lying conformers of dopamine $\mathrm{H}^{+}$. In order to evaluate which of the ions FI-FIII are likely candidates for the observed $137 \mathrm{u}$ fragment ion, the IR spectra calculated for FI-FIII are compared to the experimental IR action spectra measured in the 137, 119 and $91 \mathrm{u}$ fragment channels in Fig. S4 in ESI. $\dagger$ Both spectroscopic and energetic considerations detailed in ESI $\dagger$ tentatively suggest the 1,2-dihydroxy-2,5-cyclo-hexadienyl-4ethylidene cation (FI) to be a likely candidate. However, further mass spectrometric and spectroscopic experiments for the $137 \mathrm{u}$ species are required to confirm its structure. Such experiments $^{34}$ are beyond the scope of the present work.

\section{Conclusions}

The conformation and intramolecular interactions of protonated dopamine in the gas phase were elucidated by IRMPD spectroscopy and quantum chemical calculations. Comparison between the IRMPD spectrum in the fingerprint range and calculated linear absorption spectra of various gauche and trans conformers of dopamine $\mathrm{H}^{+}$yields good agreement for the gauche conformers $\mathbf{g}-\mathbf{1}$ and $\mathbf{g}+\mathbf{1}$, which are the energetically preferred structures in the gas phase. In these structures, protonation occurs at the N-terminus of the ethylamine side chain. The protonated amino group forms a strong intramolecular hydrogen bond to the aromatic ring (NH- $\pi$ interaction), with strong electrostatic and inductive components owing to the positive charge localized mainly at the $\mathrm{NH}_{3}{ }^{+}$group. This cation $-\pi$ binding motif has previously been identified as fundamental intra- and intermolecular binding force in biomolecular recognition. ${ }^{35}$ Comparison between B3LYP and MP2 energies indicate also significant dispersion contributions to the $\mathrm{NH}-\pi$ bond energy $\left(\sim 5 \mathrm{~kJ} \mathrm{~mol}^{-1}\right)$. Interestingly, no spectroscopic signature of trans configurations is detected in the IRMPD spectrum, although these configurations are probably the most stable conformers in the condensed phase and thus also in the solution used for the ESI spray in the present work, due to additional stabilizing interactions of the $\mathrm{NH}_{3}{ }^{+}$terminus with polar solvent molecules and counter ions. Hence, it appears that during the ESI process, these trans configurations undergo isomerization over low barriers toward the gauche isomers, which are clearly more stable in the gas phase. In this respect, it would be interesting to characterize microhydrated dopamine $\mathrm{H}^{+}$cluster ions, in order to follow the effects of the solvent molecules on the energetic order of the dopamine $\mathrm{H}^{+}$conformations as a function of the degree of solvation. Moreover, molecular dynamics simulation ${ }^{36}$ at $300 \mathrm{~K}$ including dispersion are desired to investigate the effects of finite temperature on the appearance of the IRMPD spectrum of dopamine ${ }^{+}$. Additional experimental information about the strength of the $\mathrm{NH}-\pi$ interaction and the intramolecular $\mathrm{OH}$... O hydrogen bonds could come from IR spectra of dopamine $\mathrm{H}^{+}$recorded in the $\mathrm{NH}$ and $\mathrm{OH}$ stretch ranges. Moreover, IR spectra of neutral dopamine recorded in a molecular beam using sophisticated double resonance experiments ${ }^{37}$ are desired to establish the structure of the neutral species isolated in the gas phase.

\section{Acknowledgements}

This work was supported by the Technische Universität Berlin, the Deutsche Forschungsgemeinschaft (DO 729/3), and the Fonds der Chemischen Industrie. The research leading to these results has also received funding from the European Community's Seventh Framework Programme (FP7/20072013) under grant agreement \#226716. This work is part of the research program of FOM, which is financially supported by the Nederlandse Organisatie voor Wetenschappelijk Onderzoek (NWO). We gratefully acknowledge excellent support by the FELIX staff (B. Redlich et al.).

\section{References}

1 L. Stryer, Biochemistry, Freeman, New York, 4th edn, 1996.

2 C. J. Grol, The Chemistry of Dopamine, Academic Press, New York, 1979, p. 7.

3 X. Y. Wang, B. K. Jin and X. Q. Lin, Anal. Sci., 2002, 18(8), 931.

4 S. Pande, S. Jana, A. K. Sinha, S. Sarkar, M. Basu, M. Pradhan, A. Pal, J. Chowdhury and T. Pal, J. Phys. Chem. C, 2009, 113(17), 6989.

5 P. I. Nagy, G. Alagona and C. Ghio, J. Am. Chem. Soc., 1999, 121(20), 4804, and references therein.

6 P. Solmajer, D. Kocjan and T. Solmajer, Z. Naturforsch. C: J. Biosci., 1983, 38(9-10), 758.

7 S. Kitayama, S. Shimada, H. X. Xu, L. Markham, D. M. Donovan and G. R. Uhl, Proc. Natl. Acad. Sci. U. S. A., 1992, 89(16), 7782.

8 S. K. Park, N. S. Lee and S. H. Lee, Bull. Korean Chem. Soc., 2000, 21(10), 959.

9 J. J. Urban, C. W. Cronin, R. R. Roberts and G. R. Famini, J. Am. Chem. Soc., 1997, 119(50), 12292.

10 R. Bergin and D. Carlström, Acta Crystallogr., Sect. B: Struct. Crystallogr. Cryst. Chem., 1968, 24, 1506; S. Gunasekaran, R. T. Kumar and S. Ponnusamy, Indian J. Pure Appl. Phys., $2007, \mathbf{4 5}, 884$. 
11 S. Bourcier, J. F. Benoist, F. Clerc, O. Rigal, M. Taghi and Y. Hoppilliard, Rapid Commun. Mass Spectrom., 2006, 20(9), 1405.

12 S. Bourcier and Y. Hoppilliard, Rapid Commun. Mass Spectrom., 2009, 23(1), 93.

13 P. Ostman, J. M. H. Pakarinen, P. Vainiotalo, S. Franssila, R. Kostiainen and T. Kotiaho, Rapid Commun. Mass Spectrom., 2006, 20(24), 3669.

14 E. P. L. Hunter and S. G. Lias, J. Phys. Chem. Ref. Data, 1998, 27, 413.

15 P. J. Linstrom and W. G. Mallard, NIST Chemistry WebBook, 2010, http:/webbook.nist.gov.

16 N. A. Macleod and J. P. Simons, Mol. Phys., 2006, 104(20-21), 3317; N. A. Macleod and J. P. Simons, Phys. Chem. Chem. Phys., 2004, 6, 2821; T. D. Vaden, T. de Boer, N. A. MacLeod, E. M. Marzluff, J. P. Simons and L. C. Snoek, Phys. Chem. Chem. Phys., 2007, 9(20), 2549.

17 T. D. Fridgen, Mass Spectrom. Rev., 2009, 28(4), 586; N. C. Polfer and J. Oomens, Mass Spectrom. Rev., 2009, 28(3), 468; J. R. Eyler, Mass Spectrom. Rev., 2009, 28(3), 448; M. Seydou, G. Gregoire, J. Liquier, J. Lemaire, J. P. Schermann and C. Desfrancois, J. Am. Chem. Soc., 2008, 130(12), 4187.

18 H. Knorke, J. Langer, J. Oomens and O. Dopfer, Astrophys. J. Lett., 2009, 706, L66.

19 T. R. Rizzo, J. A. Stearns and O. V. Boyarkin, Int. Rev. Phys. Chem., 2009, 28(3), 481; N. S. Nagornova, T. R. Rizzo and O. V. Boyarkin, J. Am. Chem. Soc., 2010, 132(12), 4040; M. Guidi, U. J. Lorenz, G. Papadopoulos, O. V. Boyarkin and T. R. Rizzo, J. Phys. Chem. A, 2009, 113(5), 797; A. Fujihara, H. Matsumoto, Y. Shibata, H. Ishikawa and K. Fuke, J. Phys. Chem. A, 2008, 112(7), 1457.

20 J. A. Stearns, M. Guidi, O. V. Boyarkin and T. R. Rizzo, J. Chem. Phys., 2007, 127(15), 154322.

21 L. MacAleese and P. Maitre, Mass Spectrom. Rev., 2007, 26(4), 583; O. Dopfer, J. Phys. Org. Chem., 2006, 19, 540; A. Lagutschenkov, R. K. Sinha, P. Maitre and O. Dopfer, J. Phys. Chem. A, 2010, 114, 11053; A. Lagutschenkov, A. Springer, U. J. Lorenz, P. Maitre and O. Dopfer, J. Phys. Chem. A, 2010, 114, 2073.

22 J. Oomens, B. G. Sartakov, G. Meijer and G. von Helden, Int. J. Mass Spectrom., 2006, 254, 1.

23 D. W. Zhao, J. Langer, J. Oomens and O. Dopfer, J. Chem. Phys., 2009, 131(18), 184307.

24 O. Dopfer, Report for Project FELIX-003, 2009.

25 D. Oepts, A. F. G. Vandermeer and P. W. Vanamersfoort, Infrared Phys. Technol., 1995, 36(1), 297; J. J. Valle, J. R. Eyler, J. Oomens, D. T. Moore, A. F. G. van der Meer, G. von Helden, G. Meijer, C. L. Hendrickson, A. G. Marshall and G. T. Blakney, Rev. Sci. Instrum., 2005, 76(2), 7.
26 T. H. Dunning, J. Chem. Phys., 1989, 90(2), 1007.

27 M. J. Frisch, G. W. Trucks, H. B. Schlegel, G. E. Scuseria, M. A. Robb, J. R. Cheeseman, J. A. Montgomery, Jr., T. Vreven, K. N. Kudin, J. C. Burant, J. M. Millam, S. S. Iyengar, J. Tomasi, V. Barone, B. Mennucci, M. Cossi, G. Scalmani, N. Rega, G. A. Petersson, H. Nakatsuji, M. Hada, M. Ehara, K. Toyota, R. Fukuda, J. Hasegawa, M. Ishida, T. Nakajima, Y. Honda, O. Kitao, H. Nakai, M. Klene, X. Li, J. E. Knox, H. P. Hratchian, J. B. Cross, V. Bakken, C. Adamo, J. Jaramillo, R. Gomperts, R. E. Stratmann, O. Yazyev, A. J. Austin, R. Cammi, C. Pomelli, J. W. Ochterski, P. Y. Ayala, K. Morokuma, G. A. Voth, P. Salvador, J. J. Dannenberg, V. G. Zakrzewski, S. Dapprich, A. D. Daniels, M. C. Strain, O. Farkas, D. K. Malick, A. D. Rabuck, K. Raghavachari, J. B. Foresman, J. V. Ortiz, Q. Cui, A. G. Baboul, S. Clifford, J. Cioslowski, B. B. Stefanov, G. Liu, A. Liashenko, P. Piskorz, I. Komaromi, R. L. Martin, D. J. Fox, T. Keith, M. A. Al-Laham, C. Y. Peng, A. Nanayakkara, M. Challacombe, P. M. W. Gill, B. Johnson, W. Chen, M. W. Wong, C. Gonzalez and J. A. Pople, Gaussian 03 Rev. C.02, Gaussian, Inc., Wallingford, CT, 2004.

28 B. Chiavarino, M. E. Crestoni, S. Fornarini, O. Dopfer, J. Lemaire and P. Maitre, J. Phys. Chem. A, 2006, 110, 9352.

29 T. Burgi and S. Leutwyler, J. Chem. Phys., 1994, 101(10), 8418; M. Gerhards, W. Perl, S. Schumm, U. Henrichs and K. Kleinermanns, J. Chem. Phys., 1997, 106(3), 878.

30 M. Gerhards, W. Perl, S. Schumm, U. Henrichs, C. Jacoby and K. Kleinermanns, J. Chem. Phys., 1996, 104(23), 9362.

31 H. Valdes, V. Klusak, M. Pitonak, O. Exner, I. Stary, P. Hobza and L. Rulisek, J. Comput. Chem., 2008, 29(6), 861.

32 K. E. Riley and P. Hobza, J. Phys. Chem. A, 2007, 111(33), 8257.

33 E. B. Wilson, Phys. Rev., 1934, 45(10), 706.

34 U. Erlekam, B. J. Bythell, D. Scuderi, M. Van Stipdonk, B. Paizs and P. Maitre, J. Am. Chem. Soc., 2009, 131(32), 11503.

35 D. A. Dougherty, Science, 1996, 271(5246), 163; J. C. Ma and D. A. Dougherty, Chem. Rev., 1997, 97(5), 1303; T. D. Vaden, T. de Boer, J. P. Simons and L. C. Snoek, Phys. Chem. Chem. Phys., 2008, 10(10), 1443; A. Lagutschenkov, J. Langer, G. Berden, J. Oomens and O. Dopfer, J. Phys. Chem. A, 2010, DOI: $10.1021 /$ jp109337a.

36 M. P. Gaigeot, Phys. Chem. Chem. Phys., 2010, 12(14), 3336; X. H. Li, J. Oomens, J. R. Eyler, D. T. Moore and S. S. Iyengar, J. Chem. Phys., 2010, 132(24), 244301.

37 H. Mitsuda, M. Miyazaki, I. B. Nielsen, P. Carcabal, C. Dedonder, C. Jouvet, S. Ishiuchi and M. Fujii, J. Phys. Chem. Lett., 2010, 1(7), 1130. 